\title{
The Costs of Delayed Generic Drug Entry: Evidence from a Controversial Prostate Cancer Drug Patent
}

\author{
David Miller, M.D. ' (D), Benedic Ippolito, Ph.D. ${ }^{2}$, Inmaculada Hernandez, Ph.D. ${ }^{3}$, and \\ Benjamin Davies, M.D. ${ }^{7}$
}

\begin{abstract}
${ }^{7}$ Department of Urology, University of Pittsburgh Medical Center, 5200 Centre Avenue, Suite 209, Pittsburgh, PA, USA; ${ }^{2}$ American Enterprise Institute for Public Policy Research, Washington D.C., USA; ${ }^{3}$ School of Pharmacy and Pharmaceutical Sciences, University of California San Diego, San Diego, CA, USA.
\end{abstract}

J Gen Intern Med 37(3):668-70

DOI: $10.1007 / \mathrm{s} 11606-021-07000-3$

(c) Society of General Internal Medicine 2021

$\mathrm{T}$ he 117th Congress is marked by the slimmest of Democratic majorities. Historically, narrow majorities of either party in Congress have limited significant overhauls to US pharmaceutical policy. Yet, there are meaningful and pragmatic policy changes that should attract bipartisan interest. In this piece, we highlight such a challenge by focusing on costs associated with delayed generic drug entry. Specifically, we show how a single inappropriately awarded patent cost consumers $\$ 2$ billion.

The US drug market balances the incentives to invest in new pharmaceuticals with the desire to constrain society's long run spending on drugs. Novel products are given shortrun monopolies in exchange for the eventual entry of low-cost generic drugs. However, some argue that branded manufacturers use "evergreening" strategies, where they strategically extend monopoly periods by acquiring additional patents that may have little novelty, as earlier-awarded patents are set to expire.

We focus on the high-profile case of abiraterone (Zytiga ${ }^{\circledR}$, Janssen Pharm. Inc.) to illustrate how even a later-invalidated patent can meaningfully increase drug spending. First, we describe the history of abiraterone's patents. Second, we show how sales of branded and generic abiraterone evolved through patent landmarks. Third, we discuss the potential merits of policy interventions aimed at speeding generic entry in similar cases.

Abiraterone acetate was granted an original patent for its formulation in 1994 (we refer to as "the '213 patent," in reference to the last digits of the patent number). In 2011, the FDA approved abiraterone for the treatment of metastatic castrate-resistant prostate cancer. The use of abiraterone was then further expanded in 2017 to treat patients with metastatic

Received April 21, 2021

Accepted June 23, 2021

Published online July 13, 2021 castrate-sensitive prostate cancer. Critically, abiraterone was granted a secondary patent (the ' 438 patent) covering the coadministration of abiraterone with prednisone for the treatment of cancer in 2014.

The issuance of the ' 438 patent proved highly controversial. As a CYP17A1 inhibitor, abiraterone triggers glucocorticoid deficiency and mineralocorticoid excess. The pathways of steroidogenesis have long been established in the endocrine literature and inhibiting CYP17A1 has well defined and predetermined clinical implications. ${ }^{1}$ Because of this, prednisone was widely co-administered with the drug. However, in September 2014, and on its 6th application, Janssen Pharmaceuticals was granted the " 438 patent covering the coadministration of abiraterone with prednisone.

Anticipating the expiration of the original ' 213 patent at the end of 2016, generic manufacturers filed for approval to market a generic version. Janssen immediately filed suit alleging that these manufacturers were infringing on the ' 438 secondary patent. As with all drugs, when the patent holder files suit alleging infringement, the FDA withholds its approval of the generic for up to 30 months. In October of 2018, the United States District Court ruled that the ' 438 patent was invalid because the coadministration with prednisone was deemed obvious, allowing for generic entry shortly thereafter. ${ }^{[2]}$ Despite ultimately being dismissed, the ' 438 patent extended the drug's monopoly period from December of 2016 through October of 2018.

We used data from IQVIA's National Sales Perspective ${ }^{\mathrm{TM}}$ for years 2011-2020 to illustrate market share and sales of brand and generic abiraterone. This database is derived from a projected audit covering $100 \%$ of national unit volume of purchases from manufacturers or wholesalers to pharmacies, clinics, hospitals, and other distribution outlets. IQVIA's National Sales Perspective ${ }^{\mathrm{TM}}$ also reports "dollar sales" which captures invoiced sales by wholesalers and manufacturers to pharmacies, hospitals, clinics, and other supply chain intermediaries. ${ }^{3}$ The reported "dollar sales" amount includes line-item and prompt-payment discounts but does not include offinvoice discounts such as rebates. ${ }^{3}$ To account for this, we used the SSR Health US Brand Rx Net Pricing Tool, which estimates the difference between list and net prices for branded 
drugs. ${ }^{4}$ We adjusted Zytiga sales by this percentage in each period (rebates are uncommon for non-branded drugs).

At the expiration of its initial '213 patent (December 2016), Zytiga net sales were an estimated $\$ 81$ million per month.
Monthly net revenues reached their peak of $\$ 154$ million in September of 2018. In part, this reflected expanded approval to include almost all metastatic prostate cancer patients. ${ }^{5}$ As expected, the entry of generic competitors drastically reduced

A)

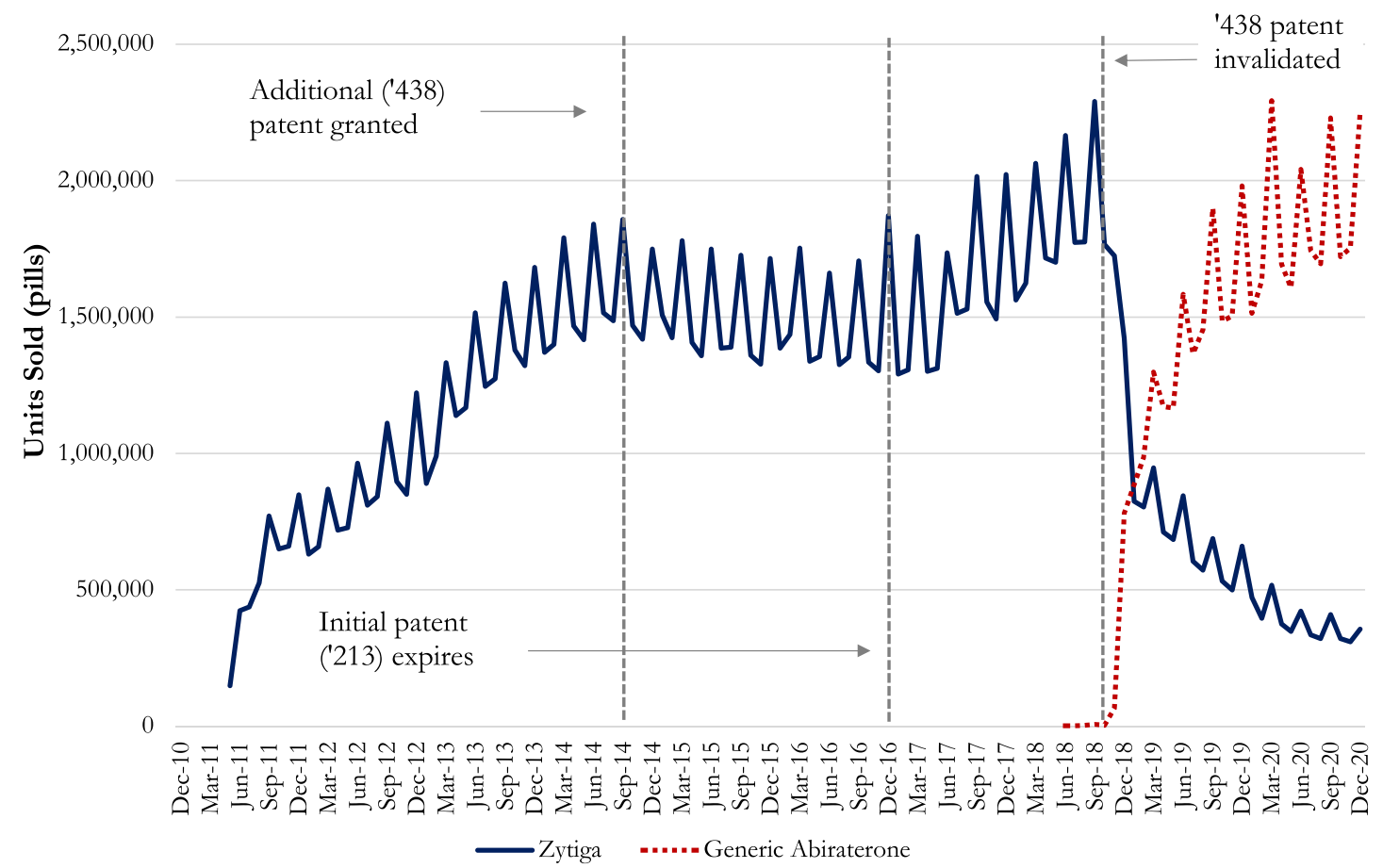

B)

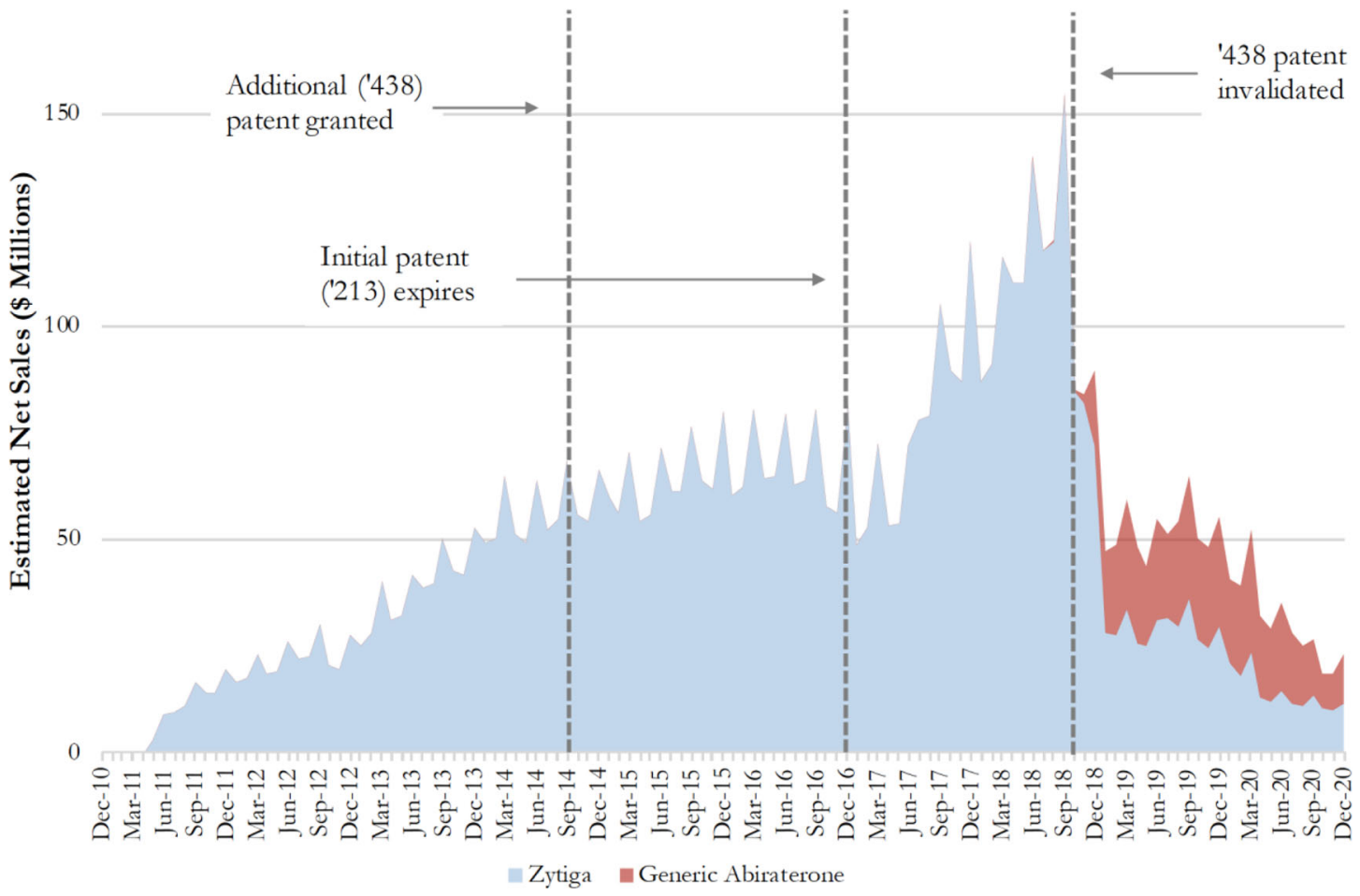

Figure 1 A This figure shows units sold (pills) of Zytiga and generic Abiraterone. B This figure shows net sales for Zytiga and generic abiraterone. Data on sales and units sold are from IQVIA for 2011-2020. Sales for Zytiga have been adjusted for estimated rebates taken from SSR Health. Increasing revenues and units sold in late 2017 reflect expanded approval following the LATITUDE trial. 
spending. By December 2020, Zytiga represented just 13.7\% of units sold (panel A, Fig. 1) with generic abiraterone representing $86.3 \%$ of units sold. Furthermore, Zytiga monthly net sales across the entire market fell roughly $85 \%$ to $\$ 23$ million in December 2020 (panel B, Fig. 1) despite a modest increase in units sold across the market.

We estimated a counterfactual for how spending would have evolved if the generic had entered in December of 2016, when the original '213 patent expired. To do so, we assumed Zytiga would have begun to lose market share (defined as units sold of Zytiga as a fraction of total units sold in the market) in December 2016. We assumed its market share would have fallen at the same rate as we observed following the actual generic entry in 2018. This implies Zytiga market share would have been just under 14\% by December of 2018 . Similarly, we assumed Zytiga's price would have evolved in the same proportion as observed following generic entry in 2018. Together, we estimate that from December 2016 to December 2020, Zytiga sales would have been $\$ 2.05$ billion lower if generic entry had occurred in December 2016. Results were similar under the simple assumption that its price was constant from that point forth.

The experience of abiraterone highlights a key challenge facing the modern drug market - delaying generic entry can be highly profitable to branded manufacturers. Importantly, even an ultimately successful patent challenge requires substantial time and has major implications for consumer spending on pharmaceuticals. To this end, a primary goal of policy should be to ensure that current patent standards are implemented accurately and efficiently so that delays associated with unmerited patents are avoided.

As a first step, Congress can pass legislation to ensure that the US Patent and Trade Office (USPTO) has enough resources to adequately assess patents according to current standards. Research has suggested that time constraints for patent examiners contributes to the issuance of laterinvalidated patents. ${ }^{6}$ Increasing resources to the USPTO wouldn't involve any change to patent standards. As the case of abiraterone illustrates, even a small decrease in the likelihood of issuing later-invalidated patents is likely to generate substantial cost savings.

Targeted changes to FDA policy might be warranted and are a potential source of Congressional bipartisan agreement. For example, the Reforming Evergreening and Manipulation that Extends Drug Years (REMEDY) Act of 2019, a bipartisan proposal, would eliminate the 30-month delay for generic entry when challenging patents that do not cover the drug's active ingredient (like Zytiga's '438 patent). Generics would still be launching "at risk" (that is, they could face litigation for patent infringement), so this should only materially affect patents that are least likely to survive a court challenge, like with the case presented here.

Others have advocated much more sweeping reforms of secondary patenting. For example, one recent presidential campaign proposed limiting pharmaceuticals to a single 20year patent. ${ }^{7}$ These proposals raise more substantial tradeoffs by targeting secondary patents more indiscriminately. Secondary patents can encourage manufacturers to pursue various types of innovations that have value - for example, a manufacturer might invest in trials to illustrate efficacy of a drug for larger populations, or in developing improved formulations of a drug (e.g., a shelf-stable formulation to help retain efficacy in suboptimal conditions ${ }^{8}$ ). However, we view the 'secondary patents encourage innovation' point as an unconvincing counterargument to policies like the REMEDY Act which specifically target the weakest patents. Allowing a certain level of non-merited patents to persist with the hope that they then spurn innovation is a poorly targeted way to encourage valuable investments.

Ultimately, the US drug market relies on timely generic entry to balance innovation incentives with cost containment. With very narrow majorities in Congress, policymakers ought to prioritize policies that retain this balance and have the potential for bipartisan consensus. Policies that target the most tenuous drug patents may not read like a major policy win, but their prosaic change will have a robust cost-containment effect - as evidenced by abiraterone's unfortunate case - that both political parties can celebrate.

Corresponding Author: Benjamin Davies, M.D.; Department of Urology, University of Pittsburgh Medical Center, 5200 Centre Avenue, Suite 209, Pittsburgh, PA 15232, USA (e-mail: daviesbj@upmc.edu).

\section{REFERENCES}

1. Melmed S, Koenig R, Rosen C, Auchus R, Goldfine A. Williams Textbook of Endocrinology. 14th ed. Elsevier; 2019.

2. BTG International Ltd. v. Amneal Pharmaceuticals LLC. F.3d(Fed. Cir. 2019).

3. Conti RM, Berndt ER. Four facts concerning competition in U.S. generic prescription drug markets. Int J Econ Bus. 2020;27(1):27-48. https://doi. org/10.1080/13571516.2019.1654324.

4. Kakani P, Chernew M, Chandra A. Rebates in the Pharmaceutical Industry: Evidence from Medicines Sold in Retail Pharmacies in the US. National Bureau of Economic Research. 2020; No. w26846.

5. Fizazi K, Tran N, Fein L, et al. Abiraterone plus prednisone in metastatic, castration-sensitive prostate cancer. N Engl J Med. 2017;377(4):352-360. https://doi.org/10.1056/NEJMoa1704174.

6. Frakes MD, Wasserman MF. Investing in ex ante regulation: Evidence from pharmaceutical patent examination. National Bureau of Economic Research; 2020

7. Drug Prices. Mike Bloomberg 2020. Published 2020. https://www. mikebloomberg2020.com/policies/drug-prices. Accessed 23 Dec 2020.

8. Amin T, Kesselheim AS. Secondary patenting of branded pharmaceuticals: A case study of how patents on two HIV drugs could be extended for decades. Health Affairs. 2012;31(10):2286-2294. https://doi.org/10. 1377 /hlthaff.2012.0107.

Publisher's Note: Springer Nature remains neutral with regard to jurisdictional claims in published maps and institutional affiliations. 